\title{
Exploring the effect of familiarity and advisory services on innovation outcomes in outsourcing settings
}

\author{
Ilan Oshri ${ }^{1}$, Daria Arkhipova ${ }^{2}$, Giovanni Vaia ${ }^{2}$ \\ ${ }^{1}$ Loughborough School of Business and Economics, Loughborough University, Loughborough, UK; \\ ${ }^{2}$ Department of Management, Ca' Foscari University Venice, San Giobbe - Cannaregio, 873, 30121 Venice, Italy \\ Correspondence: \\ I Oshri, Loughborough School of Business and Economics, Loughborough University, Loughborough, UK. \\ Tel: 07799378980; \\ E-mail: i.oshri@lboro.ac.uk
}

\begin{abstract}
Innovation through outsourcing can be hindered as a result of opportunistic behaviour. As a remedy, the extant literature encourages firms to enhance familiarity between the parties and/or consider using advisory services. In this paper, we seek to examine the effect of knowledge familiarity (client-supplier and supplier-client) and relational familiarity on innovation outcomes. Further, we also examine whether the presence of advisors improves innovation outcomes. Our results suggest that a higher degree of relational familiarity and client-supplier knowledge familiarity are associated with better innovation outcomes. We also reveal that client-supplier knowledge familiarity mediates the effect of supplier-client knowledge familiarity on innovation outcomes. We did not find support for the direct effect of advisors on innovation outcomes. Instead, the presence of advisors moderates the effect of supplier-client and relational familiarity on innovation outcomes. We consider the implications for the IS outsourcing literature and practice. Journal of Information Technology (2018). https://doi.org/10.1057/s41265-018-0052-3
\end{abstract}

Keywords: innovation; advisory services; familiarity; outsourcing

\section{Introduction}

$\mathbf{R}$ ecent years have witnessed growing interest in understanding innovation through outsourcing engagements (Weeks and Feeny, 2008; Lacity and Willcocks, 2013; Oshri et al., 2015; Su et al., 2016). Early studies have mainly focused on understanding how innovation through outsourcing emerges over time (Weeks and Feeny, 2008; Whitley and Willcocks, 2011), while more recent research has examined the effect of relational and contractual governance on the ability to achieve strategic innovation within outsourcing settings (Oshri et al., 2015). While there has been growing evidence about firms achieving innovation from their suppliers, there have also been reports about the challenges that both clients and suppliers face when seeking innovation. Indeed, one key challenge for innovation through outsourcing is information asymmetry between the parties that could result in an opportunistic behaviour by either side. Put simply, innovation through outsourcing is likely to be hampered when clients and suppliers possess limited knowledge of each other. To mitigate this risk, clients and suppliers could consider two possible strategies. One strategy is to enhance familiarity between them (Whitley and Willcocks, 2011). Familiarity is understood along three dimensions that are relevant for innovation through outsourcing, namely the client's knowledge familiarity of the supplier (C-S knowledge familiarity), the supplier's knowledge familiarity of the client (S-C knowledge familiarity) and the relational dimension (relational familiarity). We theorize that greater familiarity ( $\mathrm{S}-\mathrm{C}, \mathrm{C}-\mathrm{S}$ and relational) improves innovation outcomes within outsourcing engagements. Another strategy is to employ an advisor as an intermediary to bridge the gap between the client and supplier (Mahnke et al., 2008). Indeed, the use of advisors is likely to provide additional support to mitigate opportunistic behaviour (Mahnke et al., 2008). More specifically, Bapna et al. (2016) have illustrated the positive effect of advisors in mitigating information asymmetry, thus contributing to a collaborative mode, and better innovation outcomes (Morgan, 2017). In line with such observations and as a response to a recent call to further 
understand the role of advisors in outsourcing settings (Lacity et al., 2016), we theorize a positive effect on innovation outcomes where advisors are employed.

The research relies on 147 responses of key informants (Goo et al., 2008) from Italian and British firms that have achieved innovation through outsourcing engagements. Results suggest that relational familiarity and client-supplier knowledge familiarity are associated with better innovation outcomes. Against our assumption, supplier-client knowledge familiarity does not directly affect innovation outcomes. Instead, its effect on innovation is mediated by clientsupplier knowledge familiarity. Last but not least, advisory services do not have a direct effect on innovation outcomes on average and have different effects depending on the degree of supplier-client and relational familiarity, respectively.

This paper offers two key contributions to the IS outsourcing literature. First, against past studies that attribute greater importance to the supplier's familiarity with the client as a precondition for collaborative relationships (Whitley and Willcocks, 2011), our study shows that, as supplier-client familiarity increases, so too does clientsupplier familiarity; and it is because of client-supplier familiarity that innovation outcomes are achieved. Secondly, our paper is among the first to examine the role of advisors in the context of innovation through outsourcing. Surprisingly, the presence of advisors does not in itself affect innovation outcomes. Instead, it positively moderates the effect of supplier-client and relational familiarity on innovation outcomes.

The remainder of the paper is organized as follows: First, the literature on innovation through outsourcing, familiarity and advisors is reviewed, followed by the development of a set of hypotheses about the effect of these factors on innovation outcomes. We then present the research methods and results followed by a discussion of the findings, implications and limitations.

\section{Innovation through outsourcing: background}

One area that has gained growing attention in the IS outsourcing literature is the likelihood or not of client firms achieving innovation through outsourcing (Weeks and Feeny, 2008; Whitley and Willcocks, 2011; Lacity and Willcocks, 2013; Su et al., 2016; Oshri et al., 2015; Aubert et al., 2015; Kotlarsky et al., 2014; Tadelis, 2007). Innovation through outsourcing is "the introduction of something new that creates value for the organization that adopts it" (Whitley and Willcocks, 2011, p. 98) or "any activity that improves the client's performance" (Lacity and Willcocks, 2014, p. 72). Being one of the first studies to examine this phenomenon, Weeks and Feeny (2008) offered a useful categorization and definitions of innovation through outsourcing, in which they distinguished between IT operational, business process and strategic innovations. IT operational innovation refers to the introduction of technology changes or new technology that does not affect the business process (e.g. a new email platform), while business process innovation alters the way the business operates (e.g. a new billing system that changes the links between accounting and service fulfilment). Strategic innovation, which is the most challenging to achieve, intends to result in new products or services delivered by the supplier (Weeks and
Feeny, 2008; Oshri et al., 2015). One example of strategic innovation is the development of a dashboard tool by the supplier for its client in order to allow executives to get realtime information about the state of the business.

Innovation through outsourcing is often at odds with some principles of successful outsourcing. While innovation is characterized with uncertainty, flexibility, adaptability and creativity, successful outsourcing is driven by a high degree of certainty, detailed contracting and ability to measure performance (Aubert et al., 2015). Further, when examined in the context of outsourcing, several studies have by now showed that such innovation may emerge during the outsourcing relationships (Weeks and Feeny, 2008; Oshri et al., 2015). As such, contracts are often awarded on the basis of the supplier's ability to deliver outsourcing services (e.g. based on costs saving), while innovation, as a component within the outsourcing relationship, is likely to emerge later on during the relationship. For example, Diageo, an international firm that contracted Infosys to deliver outsourcing services, approached its supplier a few months into the contract with a request to innovate its marketing platform. Similarly, Novartis requested IBM, its supplier for IT infrastructure for a while, to innovate its supply chain network for anti-malaria medication. As Weeks and Feeny (2008) illustrated in their life cycle of an outsourcing relationship, client firms tend to move from an initial focus on costs reduction to quality, later on, and eventually to innovation.

Consequently, capabilities required to successfully deliver outsourcing may not suffice to deliver innovation. As pointed out, innovation is enabled when the supplier develops greater understanding of the client's business domain and its strategic challenges (e.g. Whitley and Willcocks, 2011). Similarly, the client needs to develop a thorough understanding of the range of technological solutions the industry and the supplier possess and align its business objectives with the supplier's in order to achieve successful innovation outcomes (Weeks and Feeny, 2008). Such deep understanding of business and technological solutions is limited at the beginning of the relationship and tends to be developed by both supplier and client in later stages, should the parties exchange knowledge and collaborate (Lacity and Willcocks, 2014).

While collaboration is a necessity for positive innovation outcomes, the study of outsourcing has, in fact, persistently emphasized the possibility that either the client or supplier will behave opportunistically (Bapna et al., 2016). One cause of an opportunistic behaviour is information asymmetries between the parties, where suppliers may have limited information about their clients' service roadmap and client firms may have limited understanding of their suppliers' capabilities (Bapna et al., 2016), thus reducing the exchange of knowledge essential for achieving innovation.

Two streams of studies have offered remedies to the challenge of opportunistic behaviour and its impact on the collaborative mode between client and supplier. The first stream of research considered strengthening the relational governance between the client and the supplier in order to mitigate opportunistic behaviour. For example, Whitley and Willcocks (2011) proposed collaborative innovation as a way to build high levels of trust, likely to lead to innovations in an outsourcing engagement. Further, they highlighted the 
importance of incentivizing the client and supplier to share information and knowledge and engage in risk-taking activities. Lacity and Willcocks (2013) echoed such observations, suggesting that innovation in outsourcing is achieved as a result of exchanges between leadership pairs from the client and the supplier sides. In particular, Lacity and Willcocks (2013) drew attention to the importance of a collaborative culture between the client and supplier teams. A more recent study by Oshri et al. (2015) found that strategic innovation is likely to be delivered by a supplier when the quality of the client-supplier relationship is high and certain commercial models, such as a joint-venture contract or clauses in the contract, are applied to mitigate opportunistic behaviour by either side. Su et al. (2016) described how Toyota North America share technologies and data architecture with its suppliers to ensure that suppliers are familiar with its architectural requirements as they innovate for Toyota. They concluded that " $[\ldots]$ close ties between the client company and its key partners enable and motivate these partners to develop knowledge and processes specific to the client so as to deliver greater value" (ibid., p. 5). This stream of studies has indeed highlighted the importance of familiarity (Weeks and Feeny, 2008; Su et al., 2016) between the client and supplier as a strategy to mitigate collaboration hazards.

A recent stream of studies has examined the role of advisors as a complementary approach aimed at reducing information asymmetries and mitigating opportunistic behaviour between the client and supplier (Lacity et al., 2016; Bapna et al., 2016; Mahnke et al., 2008). Advisors are third-party consultancies, such as KPMG and Ernst and Young (E\&Y), that usually act on behalf of the client firm providing various types of information to allow the client firm to make decisions concerning their outsourcing engagement. Mahnke et al. (2008) observed that advisors intermediate both cultural and cognitive distances between the client and supplier, thus allowing them to reduce such asymmetries. Bapna et al. (2016) highlighted the specific areas where advisors are important in reducing information asymmetry. Relevant to the innovation through outsourcing case is the role that advisory services play during the contract in monitoring suppliers' capabilities and matching them to clients' changing requirements, providing the client with information about technological solutions and mitigating against the supplier's opportunistic behaviour. Advisors, therefore, may intermediate information asymmetries that have been identified as inhibiting innovation through outsourcing (Lacity et al., 2016; Aubert et al., 2015; Weeks and Feeny, 2008).

With this in mind, we proceed to examine the effect of familiarity and the use of advisors, as two plausible strategies to mitigate opportunistic behaviour when innovation through outsourcing is sought.

\section{Theoretical foundations and hypotheses}

\section{Familiarity in is outsourcing}

Familiarity concerns the experiences accumulated by a client firm (Fandos Herrera and Flavián Blanco, 2011), in terms of frequency of use and knowledge gained (Soderlund, 2002). There has been substantial evidence that a high degree of familiarity between buyers and suppliers positively affects the buyer's performance (Lawson et al., 2008; Cousins et al.,
2006). Espinosa et al. (2007, p. 65), who examined familiarity in software development teams, claimed that "[W]orkers who are familiar with the task and its context are thought to have larger bodies of knowledge, better organization of this knowledge, and better internal representation of problems".

In the context of IS outsourcing, familiarity has so far been measured in terms of the amount spent and number of previous contracts between a client and supplier (Gefen et al., 2008). The definition of such familiarity has emphasized the "knowledge based on prior relationships and the implied future trust it brings about" (ibid., p. 533). Put simply, Gefen et al. (2008) claimed that prior relationships between the client and the supplier are likely to mitigate risks (such as information asymmetry), as trust between the parties is greater.

While past studies on (business) familiarity between clients and suppliers have been helpful in explaining its effect on outsourcing outcomes, some assumptions regarding what familiarity is can be challenged. Firstly, currently (business) familiarity is assumed to be represented as the amount spent on a contract and the number of contract renewals, with the assumption that suppliers that are not trustworthy are weeded out (Gefen et al., 2008). However, other studies have suggested that client firms may choose to retain poorly performing suppliers simply because the transaction costs involved in switching suppliers are high (e.g. Whitten and Leinder, 2006). Secondly, familiarity as a proxy of capital spent and contract renewal does not fully address innovation challenges in outsourcing as it ignores the importance of certain conditions such as unique incentives, innovation funds, joint risk mitigation strategies and governance structures imperative for collaborative innovation (Whitley and Willcocks, 2011). Consequently, we seek to further understand and conceptualize the notion of familiarity in the context of innovation through outsourcing.

\section{Familiarity in the context of innovation through outsourcing}

The relevant IS outsourcing literature on innovation through outsourcing has emphasized two key aspects that are a necessity for both the client and supplier to possess in order to achieve innovation in their outsourcing engagements. First and foremost, the extant literature has highlighted the importance of "bridging knowledge necessary to transfer ideas" (Weeks and Feeny, 2008, p. 135). Su et al. (2016) echoed this requirement, arguing for the centrality of information and knowledge exchanges between the parties as an essential condition for innovation in outsourcing. In this regard, familiarity is perceived as a product of the knowledge that each party (either the client or supplier) possesses about the other that enables information and knowledge asymmetries to be overcome, thus deflating opportunistic behaviour and promoting collaborative innovation. As such, we refer to the first notion of familiarity as knowledge familiarity, which is anchored in the knowledge that the parties have developed about each other and is associated with either the client or the supplier.

Another stream of studies has emphasized the relational aspect involved in achieving innovation through outsourcing. Based on a large-scale survey, Oshri et al. (2015) showed that high-quality client-supplier relationships improve innovation outcomes in outsourcing engagements. Further, Whitely and Willcocks (2011) emphasized the need to develop trust 
between the parties as a condition for engaging in what they termed as collaborative innovation. As a result, strong relationships between the client and supplier are likely to improve knowledge exchanges between the parties, thus supporting knowledge familiarity (Weeks and Feeny, 2008). Consequently, we see a role for relational familiarity as a second concept in this study.

Client-supplier knowledge familiarity and innovation outcomes

As argued above, innovation tends to emerge at a later stage of the outsourcing relationship (Lacity and Willcocks, 2014). As such, suppliers are likely to be chosen based on their ability to deliver cost savings rather than innovation (Weeks and Feeny, 2008). As the client firm shifts from the initial focus on costs to consider quality improvements and strategic innovation, the importance of it developing technological and business knowledge is also increasing. In particular, in order to achieve positive outcomes of innovation, the client firm needs to develop deep understanding of technological solutions held by the supplier and the market (Weeks and Feeny, 2008), as well as be able to re-define its innovation agenda. These two areas of knowledge, i.e. technological solutions and innovation agenda, allow the client firm to engage in a meaningful exchange of knowledge with the supplier, imperative to achieve positive innovation outcomes (ibid.). However, clients tend to face challenges in developing these areas of knowledge. For one, as outsourcing commences, client firms lose imperative domain knowledge to the supplier (Cullen and Willcocks, 2003), often through the transfer of staff, which depletes the client firm of critical knowledge needed to retain and further develop the firm's understanding of technological solutions. Secondly, early emphasis on cost reduction often results in the client firm's inability to shift its attention to business innovations (Weeks and Feeny, 2008). Consequently, client firms lose their ability to innovate, predominately either responding to innovations proposed by the supplier or greatly dependent on a network of partners for innovation (Aubert et al., 2015). Under such circumstances, suppliers are likely to behave opportunistically, promoting innovative solutions to their clients; however, either at premium fees beyond the value of the innovation or at high risk as the supplier's abilities to innovate are unknown to the client firm. To mitigate such risk, the extant innovation through outsourcing literature advises the client firm to maintain ongoing communications with the supplier through leadership pairs, involvement in innovation days, and a special governance structure from the early stages of the relationship (Lacity and Willcocks, 2014). At the same time, client firms need to retain strong technical organization and align the business with the IT function (Weeks and Feeny, 2008). In doing so, client firms are likely to retain technological knowledge imperative to the assessment of technological solutions, as well as retain its ability to drive innovation, thus reducing the risk of supplier opportunistic behaviour and negative innovation outcomes. We therefore argue:

H1: A higher degree of client-supplier knowledge familiarity is likely to improve innovation outcomes.
Supplier-client knowledge familiarity and innovation outcomes To achieve positive innovation outcomes, suppliers need to invest efforts in developing deep understanding of the client firm's technical and business challenges (Weeks and Feeny, 2008). At the same time, suppliers are concerned with profitability from the outsourcing engagement (Gopal and Sivaramakrishnan, 2008) and are, therefore, likely to minimize investment in activities where profitability is unclear, such as in innovations (Aubert et al., 2015). Indeed, such conflicting forces may encourage suppliers to behave opportunistically. Considering that the costs of contracting play a major role in the client firm's consideration to award a contract (Bapna et al., 2016), suppliers may attempt either to differentiate their offering on a higher value and higher fee basis or bid at slim margins where possible. Either approach is likely to result in a downward pressure on contract fees in order to win a contract (Bapna et al., 2016). Suppliers that cast their capabilities as superior to others and that have consented to shrink their margins in order to win the contract may suffer from "winner's curse" (Kern et al., 2002), when delivering outsourcing services. Consequently, suppliers will invest their efforts in meeting their profitability targets, refraining from an investment in learning about the client firm's business challenges that are imperative for the delivery of positive innovation outcomes. To address this concern, recent studies have hinted that suppliers should consider the potential returns from innovating for their clients, as opposed to pursuing opportunistic behaviour, as such returns could be significant in the long term (Morgan, 2017). However, in order to deliver impactful innovation, suppliers are required to invest in understanding the client's service value chain and its changing business objectives (Weeks and Feeny, 2008; Morgan, 2017). We therefore posit:

H2: A higher degree of supplier-client knowledge familiarity is likely to improve innovation outcomes.

\section{Knowledge familiarity: the mediation effect}

While proposing that familiarity of the supplier with the client and the client with the supplier would each have a direct effect on innovation outcomes, a case can be made for their mediation effect. Indeed, the effect of supplier familiarity with the client on innovation outcomes may in fact be influenced by the client familiarity with the supplier. In this regard, greater client familiarity with the supplier is likely to result in the client's improved ability to collaborate on innovation requirements with the supplier, based on the supplier's actual innovation capabilities. That, in turn, is likely to result in positive innovation outcomes, as innovation requirements will be designed according to a realistic assessment of the supplier's capabilities. Similarly, client familiarity with the supplier is likely to have an effect on innovation outcomes because of supplier's familiarity with the client. Here, we argue that greater supplier familiarity with the client's business challenges will result in positive innovation outcomes, mainly because the supplier will be able to tailor or source solutions suitable for the business challenges faced by the client. Further, greater supplier effort to familiarize itself with the client's business is likely to result 
in a reciprocal knowledge exchange (Bresman et al., 1999) on the client side, thus increasing the familiarity of both parties, leading to positive innovation outcomes. The leadership pair described in Lacity and Willcocks's (2014) study on innovation through outsourcing supports our theorization of bidirectional mediation effect. According to Lacity and Willcocks (2014, p. 74), innovation outcomes have significantly improved when two extraordinary individuals have led the innovation project, one from the client firm and one from the supplier. In particular, the leadership pair "enjoy working together, which some research participants described as "chemistry" that develop trust between them and enable reciprocal knowledge exchanges imperative for innovation. We therefore propose:

H3a: Client-supplier knowledge familiarity mediates the effect of supplier-client knowledge familiarity on innovation outcomes.

H3b: Supplier-client knowledge familiarity mediates the effect of client-supplier knowledge familiarity on innovation outcomes.

\section{Relational familiarity and innovation outcomes}

There has been a conventional agreement that strong relationships between client firms and suppliers are likely to improve outsourcing outcomes (Lacity et al., 2010). Among the more prominent aspects of the relational aspects are the ability to share knowledge (Rottman and Lacity, 2006), trust (Lee and Chung 2009) and past experience (Benamati and Rajkumar, 2002). In the context of innovation through outsourcing, Oshri et al. (2015) showed that a highquality client-supplier relationship is likely to increase the likelihood of achieving strategic innovation. Their study examined client-supplier relationships as a manifestation of the network created between client and supplier staff. Earlier studies (Weeks and Feeny, 2008; Whitley and Willcocks, 2011; Lacity and Willcocks, 2013) provided ample case-based support for the vitality of strong relationships when innovation is sought. For example, Whitley and Willcocks (2011) emphasized the collaborative nature of such engagements, suggesting that the client and supplier should contract based on values and behaviour, rather than the traditional contractual governance. Weeks and Feeny (2008) highlighted the role of trust and governance, based on promoting strong relationships between the parties. They also encouraged the parties to apply high levels of measurement specificity to carefully specify requirements, so the parties can "trust but also verify" their collaborative effort. Such observations suggest that:

H4: A higher degree of relational familiarity is likely to improve innovation outcomes.

\section{Advisory services, familiarity and innovation outcomes}

The previous sections have established the argument that greater familiarity between the parties would lead to better innovation outcomes in outsourcing. However, concerns have been raised about the challenges both client and supplier could face when attempting to develop technological and business familiarity of each other. A further strategy to achieve positive innovation outcomes is through the use of advisory services. Advisory services have been portrayed to be acting as intermediaries between clients and suppliers (Mahnke et al., 2008). Indeed, the innovation literature has acknowledged the role that consultancy plays in brokering knowledge (Stewart and Hyysalo, 2008). Howells (2006, p. 716) described the role of the consultant as a broker that goes beyond bringing the parties together but in fact "helps transform the ideas and the knowledge being transferred" between the client and supplier. Indeed, advisory services involved in innovation projects have been documented to assist in technology transfer and information flow between the parties and bring and diffuse new business solutions from the market to their clients (Howells, 2006; Tran et al., 2011).

It flows from the above that advisory services are able to improve the effect of relational and knowledge familiarities on innovation outcomes by deploying their brokering and technology transfer skills and expertise. In particular, as innovation outcomes require collaboration between the parties, advisors are expected to act as brokers of knowledge between clients and suppliers (Bapna et al., 2016), ensuring the exchange of knowledge concerning the client's business challenges as well as the supplier's solutions. Advisors may help overcome misalignments about project requirements, intentions, contexts, motivations and mutual capabilities, thus bridging information asymmetries between the parties. Evidence indeed has shown that advisors assist suppliers to secure higher annual revenues with higher likelihoods of contract growth (Bapna et al., 2016), thus may further mitigate opportunistic behaviour from the supplier.

On the other hand, advisors may have a negative influence on the effect of relational and knowledge familiarity on innovation outcomes. Acting on behalf of the client, advisors may make the bidding process more competitive (Bapna et al., 2016), thus creating a "bidding war" between suppliers that is likely to depress profitability for the winning supplier. As suppliers are predominately concerned with securing their profitability targets, such a win could drive a supplier to focus on delivering by the contract and refraining from knowledge exchange activities, such as increasing familiarity with the client's business challenges, where the returns are unclear. Further, the presence of advisors may elevate the moral hazard between the supplier and the client, as advisors may challenge the supplier's conventions and practices. Under such conditions, advisors may be considered by the supplier as undermining its position within the relationship, resulting in a competitive rather than a collaborative setting. We therefore posit:

H5: The use of advisors will influence the strength of the relationship between client-supplier knowledge familiarity and innovation outcomes.

H6: The use of advisors will influence the strength of the relationship between supplier-client knowledge familiarity and innovation outcomes.

H7: The use of advisors will influence the strength of the relationship between relational familiarity and innovation outcomes. 
The conceptual model depicted in Figure 1 provides a graphical representation of our hypotheses.

\section{Data and method}

\section{Sample and data collection}

To examine the effects of familiarity on innovation outcomes in outsourcing arrangements, we conducted a survey of 147 client firms (hereafter referred to as clients) that had recently achieved or attempted to achieve innovation in their outsourcing projects. The unit of analysis was the specific project that was carried out for the client by one of its outsourcing partners (hereafter referred to as suppliers).

The survey was administered by an external organization based in the UK that was contracted by the authors. One of the authors worked closely with the market research firm to clearly communicate the objectives of the study and validate the list of firms to be included in the panel. During this process, several firms were omitted from the panel on various grounds such as being an outsourcing supplier. In addition, the authors reviewed entries from the pilot study and consequently omitted several entries on the grounds of unsuitable innovation for this study as well as random responses. These entries were consequently replaced by the market research firm.
The main criterion that qualified a particular respondent within a client firm for inclusion in our survey was his or her active involvement in managing the outsourcing relationship with a supplier. Furthermore, we were interested only in those outsourcing arrangements that aimed at innovation as opposed to the cases when standardized service delivery was expected from suppliers. To that end, we used a set of screening questions to ensure that each respondent in his/her current role (a) had substantial experience with the business process or IT outsourcing to third-party suppliers; (b) was sufficiently familiar with how outsourcing services were planned, delivered and evaluated within the client firm; and (c) had pursued innovation through outsourcing. Failure to respond affirmatively to any of the three screening questions resulted in a respondent being excluded from the survey.

The final sample consisted of 74 UK-based and 73 Italybased firms. The industry distribution of firms in our survey was as follows: retail, distribution and transport $(25.17 \%)$, manufacturing (24.49\%), financial and professional services (17.69\%), public sector $(14.29 \%)$, ICT $(8.84 \%)$. The remaining $9.52 \%$ were split between firms that did not fit into any of the aforementioned industry classifications. The sample was mostly composed of medium- and large-sized companies: $29.93 \%$ of firms could be classified as medium-large (250-999 employees); large (1000-3000 employees); and extremely large (more than 3000 employees) accounted for

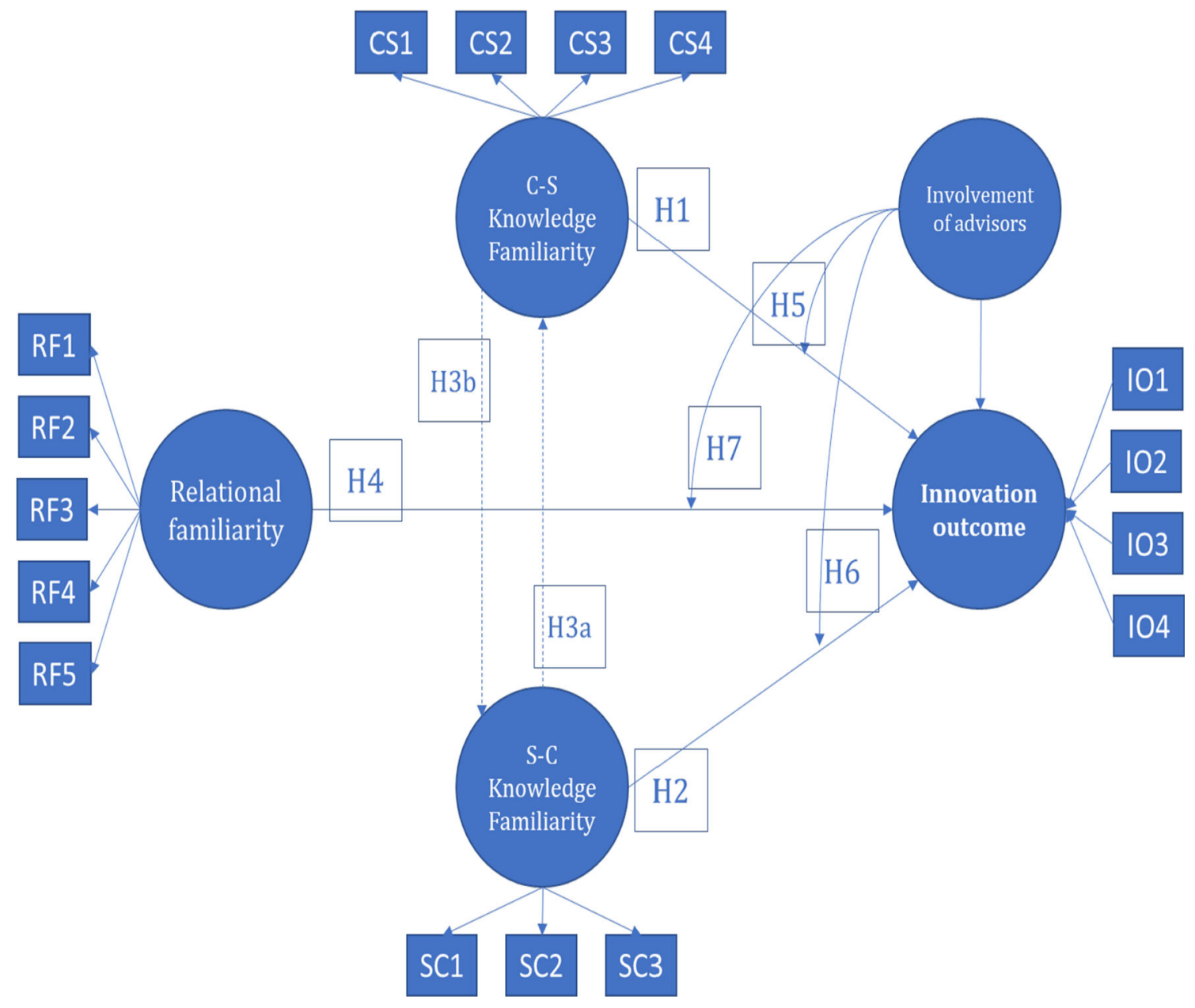

Figure 1 Conceptual path model. 
Table 1 Sample characteristics

\begin{tabular}{lcc}
\hline Sample characteristics & Frequency & Percentage \\
\hline Country & & \\
UK & 74 & 50.34 \\
Italy & 73 & 49.66 \\
Industry sector & & \\
Retail, distribution and transport & 37 & 25.17 \\
Manufacturing & 36 & 24.49 \\
Financial and professional services & 26 & 17.69 \\
Public sector & 21 & 14.29 \\
ICT & 13 & 8.84 \\
Others & 14 & 9.52 \\
Firm size & & \\
Small (< 250 employees) & 12 & 8.16 \\
Medium-large (250-999 employees) & 44 & 29.93 \\
Large (1000-3000 employees) & 46 & 31.16 \\
Extremely large (> 3000 employees) & 45 & 30.61 \\
\hline
\end{tabular}

31.29 and $30.61 \%$ of our sample, respectively. The share of small-sized companies (less than 250 employees) in our study was $8.16 \%$. The main characteristics of the sample are reported in Table 1.

\section{Endogenous variable}

Our central variable of interest was innovation outcomes in outsourcing as perceived by the client firms. As our definition of innovation through outsourcing is broad and could encompass various categories, we focused on the outcomes of supplier-led innovations, such as the frequency of the innovation, quality of the innovation and other performance parameters. In specific, each respondent was asked to express his or her agreement with a series of pre-defined statements with regard to (a) the quality of innovative solution(s) delivered through outsourcing by the supplier; (b) the frequency with which innovative solution(s) were developed; (c) cost savings; and (d) service/product improvements obtained as a result of the innovative solution(s). To measure this construct, we employed a seven-point Likert scale for this construct with scale anchors " 1 " corresponding to "strongly disagree" and " 7 " to "strongly agree" evaluations by the respondents. The composite score for the construct was calculated as a sum of its indicator scores and was treated as interval data for the subsequent statistical analysis.

\section{Exogenous variables}

To capture familiarity asymmetry in outsourcing arrangements, we discerned between two types of familiarity in our study: (1) client-supplier knowledge familiarity and (2) supplier-client knowledge familiarity. To measure the former, we used a four-item seven-point Likert scale to evaluate the extent to which the client (1) was aware of the strategic goals the supplier was pursuing in an outsourcing deal; (2) was able to assess whether the supplier was capable of delivering an innovative solution; (3) was familiar with the methodologies that the supplier was applying; and (4) understood the supplier's capabilities that were critical for delivering a particular service.
Supplier-client knowledge familiarity was measured as perceived by the client. To that end, we used a three-item seven-point Likert scale to assess to what extent a supplier, from a client's perspective, (1) possessed in-depth knowledge of the client service outsourced; (2) was aware of the business processes related to the client service outsourced; (3) was aware of the strategic goals that were pursued by the client when the service was outsourced.

Prior empirical studies have measured familiarity in client-supplier relationships as a number of repeated interactions with the same supplier (Gefen et al., 2008), or as an average number of times each pair of team members worked together previously (Espinosa et al., 2007; Huckman et al., 2009). In our view, although these measures account for the role of past experience in increasing knowledge familiarity, they might not fully capture the relational aspects of the client-supplier relationship. In this paper, we have undertaken a more granular approach towards defining the construct of relational familiarity and identified five indicators which measured: (1) the extent to which the supplier was treated as an equallevel innovation partner by the client; (2) the continuity of the client-supplier relationship; (3) the degree of physical proximity between the two teams in performing projectrelated work; (4) the strength of inclusive culture in the client-supplier relationship; (5) the degree of openness between the two parties in discussing innovative solutions.

Furthermore, the respondents were explicitly asked to state whether they had involved third-party advisory firms to mediate their relationship with suppliers. We included advisors as a dummy variable that took a value of 1 if a client firm relied on advisory services in managing an outsourcing project and 0 otherwise. Whenever the respondent was not aware of whether advisors had been used (i.e. selected the "I do not know" response option), the value of the advisors variable was set to missing. Finally, to account for the differences in quality of innovation that might have arisen owing to the country of origin, we included country as a dummy variable that used UK as a baseline category.

\section{Construct measurement and validation}

To the best of our knowledge, no well-established scales for measuring the construct of familiarity has been developed till now and most of the prior work has relied on proxy measures (Gefen et al., 2008). While we acknowledge the benefits associated with using a proxy, we believe that measuring a multifaceted construct such as familiarity by a single variable might be limiting. In our study, we seek to address this shortcoming by developing the specific measurement scales for our variables of interest. Construct measures were derived from the related theory and then refined based on discussions with practitioners and academics. Measures relating to knowledge familiarity constructs were derived from studies that examined innovation through outsourcing in the IS literature. For example, Feeny and Weeks (2008) emphasized the importance of the supplier's understanding of the client's business, the alignment in objectives between the client and the supplier, and the importance of the client's understanding of the supplier's capabilities. Similarly, Whitley and Willcocks 
(2011) highlighted the importance of aligning objectives as well as learning about the partner's business objectives, methodologies and systems. Studies have persistently emphasized the relational dimension between the parties as crucial for innovation outcomes, suggesting that frequent interactions, proximity and a partnership-based approach are likely to result in better innovation outcomes (Lacity and Willcocks, 2014; Oshri et al., 2015). Innovation outcomes have been discussed in numerous studies that pointed out the relevance of costs savings, business improvements and the quality of the solutions delivered (Weeks and Feeny, 2008; Morgan, 2017). Building on these observations, we developed our construct measures for knowledge and relational familiarity. The construct measures were examined by five managers (three from the UK and two from Italy) and two academics versed in the subject, and feedback provided helped us to refine the construct measures. Last but not least, we conducted a pilot with 16 participants (eight from each country) that confirmed that the scales were reliable and appropriate to be used in the field study.

In the case of our dependent variable (innovation outcomes), the indicators were formative as the focal construct could be thought of as a function of its observed sub-dimensions (Cenfetelli and Bassellier, 2009). That is, variance in the focal construct was caused by variance in its indicators and did not necessarily require the entire set of observed indicators to co-vary. In contrast, we used reflective indicators to measure our client-supplier, supplier-client and relational familiarity constructs. If the reflective scale was used, the indicators were conceived of as "manifestations" of the focal construct and an increase in the focal construct caused all its constituent sub-dimensions to change in the same direction (MacKenzie et al., 2011).

To establish the validity of measures employed in this study, we conducted a series of tests using the partial least squares structural equation modelling (PLS-SEM) approach. The PLS technique was argued to be more suitable for our purpose because, unlike more widespread covariance-based SEM procedures, it did not place strict requirements on a minimal sample size and allowed combining reflective and formative indicators in a single model (Chin, 1998).

We followed a procedure recommended by Cenfetelli and Bassellier (2009) to assess the validity of our formatively measured construct. Two sets of criteria were used: (1) indicator weights, i.e. the partial effect of the indicator on the construct, and (2) variance inflation factors (VIFs), i.e. the measure of collinearity among the indicators (see Table 2). Because PLS-SEM does not assume that the data are normally distributed, a nonparametric bootstrapping is used to test the

Table 2 Validity assessment criteria for the formative construct

\begin{tabular}{lll}
\hline Formative construct: indicators & Weight & VIF \\
\hline Innovation outcomes & & \\
1. Innovation quality & $0.364^{\star * *}$ & 1.742 \\
2. Innovation frequency & $0.319^{\star * *}$ & 1.311 \\
3. Cost savings & $0.306^{\star * *}$ & 1.635 \\
4. Service improvements & $0.325^{\star * \star}$ & 1.402 \\
${ }^{* \star *} p<0.01$. & &
\end{tabular}

significance of the model parameters discussed hereafter (Hair et al., 2011). With respect to innovation outcomes, all constituent indicator weights were statistically significant at $p<0.01$. The VIF values did not exceed the accepted threshold of 3.33 (Diamantopoulos and Siguaw, 2006), thus indicating that there was no problem of conceptual redundancy among the chosen indicators.

With respect to our reflective indicators, we carried out a series of tests to examine their construct reliability, convergent as well as discriminant validity. Table 3 reports indicator factor loadings, Cronbach's $\alpha$, composite reliability (CR) and average variance extracted (AVE).

To measure internal consistency between the chosen set of indicators, we computed Cronbach's $\alpha$ and composite reliability scores (Fornell and Larker, 1981). In both cases, the calculated values exceeded the commonly accepted threshold of 0.7 for each construct, thus indicating that the reliability of the measurements was likely to be sufficiently strong. To establish convergent validity, we examined the factor loadings and computed the average variance extracted (AVE). As it can be inferred from Table 3, with the exception of one, factors loadings exceeded the recommended cut-off level of 0.7 and were statistically significant at $p<0.01$, with the exception of the "physical proximity" item whose factor loading - albeit significant - falls slightly below the 0.7 threshold. The average variance extracted (AVE) measures the amount of variance captured by the focal construct from its indicators relative to the measurement error (Chin, 1998; Fornell and Larcker, 1981) and should be greater than 0.5 to ensure that the constructs account for more than $50 \%$ of the variance in its indicators (MacKenzie et al., 2011). The reported AVE values met this criterion (Table 3 ).

To understand whether discriminant validity between our constructs had been established, we relied on cross-factor loadings, Fornell-Larcker criterion (Fornell and Larcker, 1981) and the heterotrait-monotrait (HTMT) ratio of correlations (Henseler et al., 2015). With regard to crossloadings, the conventional rule is that each indicator (or each block of indicators) should load higher on the focal construct it is intended to measure than on the other constructs. Our results (not reported here) showed that the difference between factor loadings and cross-factor loadings was larger than 0.2 for all indicators, hence indicating the presence of discriminant validity. Alternatively, according to the Fornell-Larcker criterion, discriminant validity is believed to be established if the square root of AVE exceeds the pairwise correlations between all constructs. The values of $\sqrt{A V E}$ and the correlations are reported on the matrix diagonal and in the lower triangular, respectively, in the left-hand side of Table 4. For all constructs, the FornellLarcker criterion was met.

The HTMT method calculates the ratio between the average of the correlations between indicators measuring different constructs (i.e. heterotrait-heteromethod correlations) relative to the average correlations between indicators measuring the same construct (i.e. monotrait-heteromethod correlations). With regard to the most conservative HTMT criterion, HTMT values should not exceed the 0.85 threshold. In our case, all HTMT values were below the critical value (see the right-hand side of Table 4). We can therefore conclude that discriminant validity was established based on cross-loadings, Fornell-Larcker and HTMT criteria. 
Table 3 Convergent validity assessment criteria for the reflective constructs

\begin{tabular}{|c|c|c|c|c|}
\hline Reflective constructs: indicators & Factor loadings $\left({ }^{* * *} p<0.01\right)$ & Cronbach's $\alpha$ & $C R$ & $A V E$ \\
\hline Client-supplier knowledge familiarity & & 0.784 & 0.860 & 0.607 \\
\hline Familiarity with project-specific capabilities & $0.798^{\star * *}$ & & & \\
\hline Familiarity with methodologies & $0.724^{* * *}$ & & & \\
\hline Ability to assess capability to innovate & $0.759^{* * *}$ & & & \\
\hline Supplier-client knowledge familiarity & & 0.876 & 0.924 & 0.802 \\
\hline Familiarity with client strategic goals & $0.858^{\star \star *}$ & & & \\
\hline Relational familiarity & & 0.795 & 0.861 & 0.555 \\
\hline Equal treatment & $0.775^{\star * *}$ & & & \\
\hline Relationship continuity & $0.725^{\star * *}$ & & & \\
\hline Physical proximity & $0.634^{* * *}$ & & & \\
\hline
\end{tabular}

Table 4 Discriminant validity assessment criteria for the reflective constructs. Off-diagonal values are the correlations between the constructs in our model

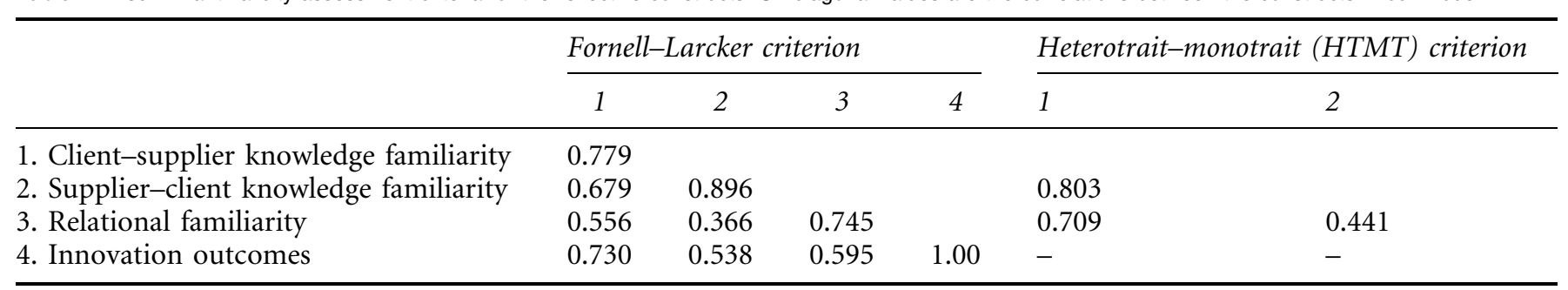

\section{Analysis and results}

We proceed with a PLS path modelling approach to analyse the hypothesized causal relations between our higher-order latent constructs (Table 5). We start by examining the model that simultaneously measures the direct effects of clientsupplier and supplier-client knowledge familiarity as well as relational familiarity on innovation outcomes (see model 1). The three variables jointly explain $62 \%$ of the total variance in innovation outcomes $\left(R^{2}=0.62, p<0.01\right)$. Our results indicate that both client-supplier knowledge familiarity $(\beta=0.477, p<0.01)$ and relational familiarity $(\beta=0.257$, $p<0.01$ ) have a positive and significant impact on innovation outcomes, thus providing support for Hypotheses 1 and 4, respectively. Contrary to our expectations, however, we find no empirical evidence for the direct effect of supplier-client knowledge familiarity on innovation outcomes $(\beta=0.088, p=0.315)$ and refute Hypothesis 2 .

In order to test our mediation hypotheses, we add a path between client-supplier and supplier-client knowledge familiarity constructs (models $2 \mathrm{a}$ and $2 \mathrm{~b}$ ). The difference between models $2 \mathrm{a}$ and $2 \mathrm{~b}$ reflects the hypothesized bidirectional nature of the relationship between the two variables: in model $2 \mathrm{a}$, the path is directed from supplier-client to clientsupplier knowledge familiarity; in model $2 \mathrm{~b}$, this direction is reversed.

The results of model 2a support Hypothesis $3 \mathrm{a}$ and indicate that the relationship between supplier-client knowledge familiarity and innovation outcomes is fully mediated by client-supplier knowledge familiarity: we observe strong positive relationships both between supplier-client knowledge familiarity and client-supplier knowledge familiarity $(\beta=0.679, p<0.01)$ and between client-supplier knowledge familiarity and innovation outcomes $(\beta=0.465$, $p<0.01$ ). In addition, we carry out a Sobel test to establish the statistical significance of the observed mediation effect $(t=4.317, p<0.01)$. This mediation effect appears to be robust across all reported model specifications suggesting that, on average, the familiarity of the supplier with the client per se is not sufficient for the client to perceive the project outcomes as innovative. Instead, for the supplier's knowledge of the client to result in innovation, the client needs to be familiar with the supplier's knowledge as well.

Conversely, if the path direction is reversed (see model $2 \mathrm{~b}$ ), we find no evidence for Hypothesis 3b: albeit the path between supplier-client and client-supplier knowledge familiarity variables is strongly positive $(\beta=0.679, p<0.01)$, the path connecting supplier-client knowledge familiarity and innovation outcomes is not $(\beta=0.077, p=0.386)$.

Finally, models $3 \mathrm{a}$ and $3 \mathrm{~b}$ include the interaction terms between three latent predictor variables and advisory services. We use a two-stage calculation method for constructing the interaction terms (Garson, 2012). With respect to clientsupplier knowledge familiarity, we find that, while its direct path coefficient remains positive and significant $(\beta=0.409$, $p<0.01$ ), no moderating effect of advisory services is observed. That is, the magnitude of the effect of the clientsupplier knowledge familiarity on innovation outcomes is not affected by the client's choice to use advisory services in its outsourcing project. Hence, Hypothesis 5 is not supported. 


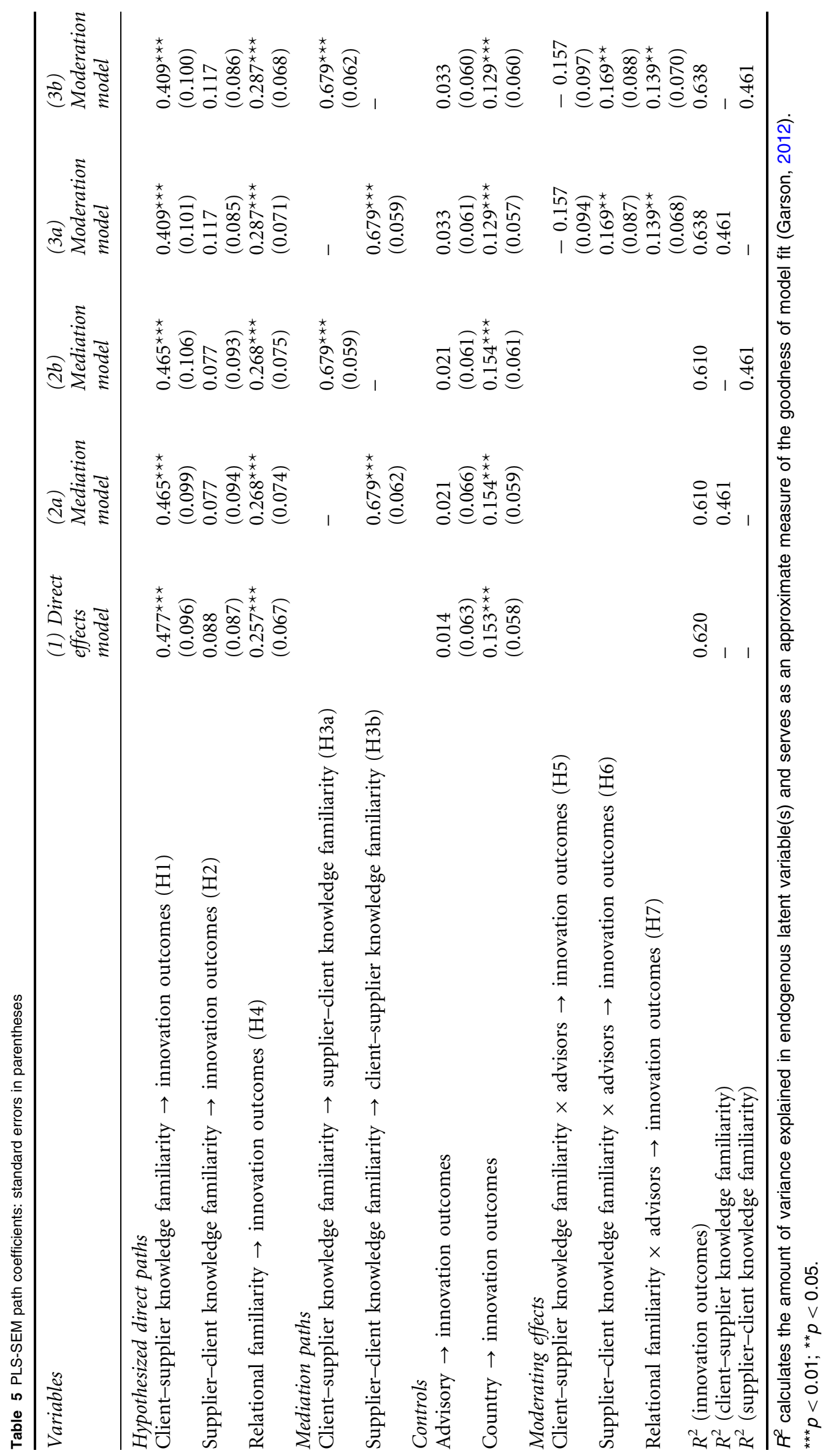


With regard to supplier-client knowledge familiarity (Hypothesis 6), we find that the moderating effect of advisory services on the relationship between supplier-client familiarity and innovation outcomes is positive and moderately significant $(\beta=0.169, p<0.05)$, whereas the main effects for neither the latent predictor variable nor the moderator variable are statistically significant $(\beta=0.117$ $(p=0.171)$ and $\beta=0.033(p=0.591)$, respectively). Such instances typically indicate the presence of what is generally called crossover interaction that implies the direction of the moderating effect differs depending on the value of the predictor variable. That is, while neither advisors nor supplier-client knowledge familiarity has a significant effect on innovation outcomes on average, using advisory services may improve (worsen) the innovation outcomes when suppliers have above-average (below-average) levels of knowledge familiarity of the client. Our results thus suggest that Hypothesis 6 is supported for the projects with a high degree of supplier-client knowledge familiarity.

Finally, it can be inferred from Table 5 that both the main effect of relational familiarity and its interaction effect with advisory services on innovation outcomes are positive and significant $(\beta=0.287, p<0.01$ and $\beta=0.139, p<0.05$, respectively), thus providing support for Hypothesis 7 . The interpretation behind these results is as follows: the greater the relational familiarity between the client and the supplier, the greater are the improvements in innovation outcomes that the involvement of third-party advisory services will entail.

\section{Discussion}

Our main interest was to examine the effect of two possible strategies to improve the outcomes of innovation through outsourcing, namely via (i) greater familiarity between the client and supplier and (ii) by the use of advisory services. Our departure point is that either side may behave opportunistically, mainly because of information asymmetries between the parties (Bapna et al., 2016), resulting in difficulties in creating the necessary conditions to achieve innovation through outsourcing. Indeed, enhancing familiarity between the client and supplier has been reported to mitigate such risk (Weeks and Feeny, 2008; Lacity and Willcocks, 2014; Oshri et al., 2015), but also recent studies have suggested that the use of advisors, as intermediary and knowledge brokers, would yield a similar effect (Mahnke et al., 2008; Lacity et al., 2016). Nonetheless, so far, the extant literature has been considered each strategy in isolation, shedding little light on the effect of each strategy on innovation outcomes and on the possible interactions between advisors and familiarity types.

Our results partially support our assumptions about the effect of familiarity (supplier-client knowledge familiarity, client-supplier knowledge familiarity and relational familiarity) on innovation outcomes. Indeed, we find support for the direct effect of relational familiarity on innovation outcomes, thus confirming past observations that innovation through outsourcing is likely to be more successful in the presence of trust and collaboration between the parties (Lacity and Willcocks, 2014; Oshri et al., 2015). Strong relational familiarity between the parties would encourage appropriate conditions for collaboration (Gopal and Koka, 2012), mitigating opportunistic behaviour from either party. Relational familiarity may allow the parties to make adjustments to their information exchange procedures without incurring additional fees, when adaptations to procedures or systems are made by either side. As such, we support past studies (Weeks and Feeny, 2008; Lacity and Willcocks, 2013) that strong relational familiarity may indeed have a positive effect on the exchange of information, thus improving innovation outcomes.

In terms of knowledge familiarity, our study sheds light on past observations in the literature that achieving innovation through outsourcing requires "a common base of prior related knowledge between the partners" (Weeks and Feeny, 2008, p. 135). In this regard, our study refines such an observation by examining the direct effect of the client's familiarity of the supplier, as well as the supplier's familiarity of the client. We show that the client's familiarity with its supplier is associated with improved innovation outcomes. On the other hand, increased supplier's familiarity with the client does not directly lead to improved innovation outcomes, with the caveat that our perceptive measure of supplier-client familiarity may not fully represent how well suppliers know their clients.

Furthermore, instead of direct effect of familiarity on innovation outcomes, we observe a slightly more complex causal mechanism at work. As the supplier becomes more familiar with the client's business during the outsourcing relationship, the client familiarizes itself better with the supplier's capabilities and this, in turn, becomes beneficial in terms of innovation outcomes for the project. The reverse causal explanation was not supported by our data. That is, even if increased client's familiarity results in corresponding increase in supplier familiarity, the latter per se does not improve the outcomes of innovation-focused outsourcing projects. Interestingly, reciprocal knowledge exchange and familiarity between the client and supplier are conditional to the client's initial investment in learning about the supplier. In this regard, the client's familiarity with the supplier would signal strong technological knowledge within the retained organization that would allow the client firm to properly assess the range of solutions that are suitable for its business challenges and that can be either developed or sourced by the supplier.

Our results also show that the presence of advisors, as a stand-alone factor, has no effect on innovation outcomes. While past studies have highlighted that utilizing advisors as knowledge brokers (Mahnke et al., 2008; Bapna et al., 2016) that may encourage collaborative engagement, thus resulting in innovation, our study did not find support for such an assertion. This suggests that the contribution of advisors to achieving innovation may come into effect subject to other conditions, such as the degree to which the client and the supplier are familiar with each other. Indeed, while our results did not support a direct effect of advisors on innovation outcomes, we do find partial support for the complementary effect of advisors on familiarity. Our results show that the effect of the supplier's familiarity with the client on innovation outcomes is stronger in the presence of advisors if the level of familiarity is sufficiently high. Similarly, the presence of advisors improves innovation outcomes if the level of relational familiarity is high. Such results suggest that these types of familiarity (i.e. S-C and relational) benefit from the presence of advisors only when the supplier is sufficiently familiar with the client's business objectives, systems and methodologies as well as when there 
is relational harmony between the parties. As such, the contribution of advisors to outsourcing engagements as an intermediating agent (Bapna et al., 2016; Mahnke et al., 2008) is conditional to the already established understanding between the client and supplier, as well as to the supplier's prior knowledge of the client. Contrary to existing studies about the role of advisory services in outsourcing engagements, advisors are unlikely to positively affect innovation outcomes unless such preconditions exist.

\section{Implications and limitations}

There are numerous theoretical and practical implications from our study. First, our study contributes to understanding the role of familiarity in the context of IS outsourcing engagements. We build on the few past empirical studies (Gefen et al., 2008) and further develop the concept of familiarity to suit the context of innovation. Our conceptualization of familiarity allowed us to model and test the effect of three types of familiarity (relational, supplier-client and client-supplier), as well as the mediating effect of knowledge familiarity on innovation outcomes. Our results shed additional light on the role that familiarity plays in enhancing innovation through outsourcing. We discover that, in terms of knowledge familiarity, the supplier's knowledge is beneficial in terms of innovation only when the client is familiar with the supplier. As such, we refine past studies about the nature of knowledge asymmetries between the client and supplier, to demonstrate the nature of interdependencies between these two types of familiarities.

Secondly, our results also have implications for the growing interest in the role of advisors. The study of advisory services in IS outsourcing has so far been provided a broad indication for their positive effect on mediating cultural and cognitive issues between the client and offshore supplier (Mahnke et al., 2008) and their positive effect on the supplier's revenue (Bapna et al., 2016). Our study shows that advisory services are also an imperative agent in mitigating opportunistic behaviour, particularly benefiting the supplier's familiarity with the client and the relational familiarity between the parties.

From a practical viewpoint, our study shows that the client and the supplier should equally invest in developing familiarity with each other's methodologies and systems. However, our study suggests that, for the supplier's familiarity to be effective, the client has to make an equal effort in familiarizing itself with the supplier's goals and abilities to innovate.

Last but not least, interestingly, advisors usually act on behalf of the client firm; however, our study shows that, in the case of innovation, advisors may strengthen the impact of the supplier's familiarity with the client on innovation outcomes. As such, clients should be mindful that one possible benefit of contracting advisory services is to allow the advisor to work closely with the supplier in order to enhance the supplier's knowledge of the client.

This study has several limitations. First, the supplier's familiarity of the client is a perceptual construct which was provided by an informant from the client firm and thus does not reflect the actual supplier's familiarity of the client. Future research should consider designing such a study by sampling informants from both clients and suppliers, ideally of the same outsourcing engagement. Secondly, our sample is based on informants from Italy and the UK. While additional tests we carried out to control for the two populations did not yield major concerns about the effect of these different populations, there are still concerns that some unique features of these two countries may have had an effect on the results of this study. Future studies should either focus on a single country sample or increase the sample per country to allow a reliable testing of certain characteristics of each population with a much bigger sample.

\section{Notes}

1. http://www-935.ibm.com/services/multimedia/WR925831EDJLR_MIS_dashboard_GBC03090GBEN.pdf.

2. www.infosys.com/industries/consumer-packaged-goods/casestudies/Pages/new-digital-consumer-connections.aspx.

3. www-03.ibm.com/press/us/en/pressrelease/29022.wss and www. malaria.novartis.com/innovation/sms-for-life/.

4. An alternative way to measure supplier-client familiarity would be to pair-match each client firm with its respective outsourcing provider and collect the responses to the same series of questions from the latter. Due to the anonymous nature of our survey, however, neither clients' nor suppliers' names have been disclosed, thus precluding us from following this route.

5. Ringle, Christian M., Wende, Sven, and Will, Alexander (2005). SmartPLS 2.0.M3. Hamburg: SmartPLS, http://www.smartpls.de.

\section{References}

Aubert, B., Kishore, R. and Iriyama, A. (2015). Exploring and Managing the 'Innovation Through Outsourcing' Paradox, Journal of Strategic Information Systems 24(4): 255-269.

Bapna, R., Gupta, A. and Rayet, G. (2016). IT Outsourcing and the Impact of Advisors on Clients and Suppliers, Information Systems Research 27(3): 636-647.

Benamati, J. and Rajkumar, T.M. (2002). The Application Development Outsourcing Decision: An Application of the Technology Acceptance Model, The Journal of Computer Information Systems 42(4): 35-43.

Bresman, H., Birkimshaw, J. and Nobel, R. (1999). Knowledge Transfer in International Acquisitions, Journal of International Business Studies 30(3): 439-462.

Cenfetelli, R.T. and Bassellier, G. (2009). Interpretation of Formative Measurement in Information Systems Research, MIS Quarterly 33(4): 689-707.

Chin, W.W. (1998). The Partial Least Squares Approach to Structural Equation Modeling, Modern Methods for Business Research 295(2): 295-336.

Cousins, P.D., Handfield, R.B., Lawson, B. and Petersen, K.J. (2006). Creating Supply Chain Relational Capital: The Impact of Formal and Informal Socialization Processes, Journal of Operations Management 24, 851-863.

Cullen, S. and Willcocks, L. (2003). Intelligent IT Outsourcing: Eight Building Blocks to Success, Oxford: Butterworth.

Diamantopoulos, A. and Siguaw, J.A. (2006). Formative Versus Reflective Indicators in Organizational Measure Development: A Comparison and Empirical Illustration, British Journal of Management 17(4): 263-282.

Espinosa, J.A., Slaughter, S.A., Kraut, R.E. and Herbsleb, J.D. (2007). Team Knowledge and Coordination in Geographically Distributed Software Development, Journal of Management Information Systems 24(1): 135-169.

Fandos Herrera, C. and Flavián Blanco, C. (2011). Consequences of consumer trust in PDO food products: The role of familiarity, Journal of Product \& Brand Management 20(4): 282-296.

Fornell, C. and Larcker, D.F. (1981). Evaluating Structural Equation Models with Unobservable Variables and Measurement Error, Journal of Marketing Research 18(1): 39-50.

Garson, D. (2012). Partial Least Squares: Regression and Path Modeling, Asheboro, NC: Statistical Publishing Associates. 
Gefen, D., Wyss, S. and Lichtenstein, Y. (2008). Business Familiarity as Risk Mitigation in Software Development Outsourcing Contracts, MIS Quarterly 32(3): 531-551.

Gopal, A. and Koka, B. (2012). The Asymmetric Benefits of Relational Flexibility: Evidence From Software Development Outsourcing, MIS Quarterly 36(2): 553-576.

Gopal, A. and Sivaramakrishnan, K. (2008). On Vendor Preferences for Contract Types in Offshore Software Projects: The Case of Fixed Price vs. Time and Materials Contracts, Information Systems Research 19(2): 202-220.

Goo, J., Huang, C.D. and Hart, P. (2008). A Path to Successful IT Outsourcing: Interaction Between Service-Level Agreements and Commitment, Decision Sciences 39(3): 469-506.

Hair, J.F., Ringle, C.M. and Sarstedt, M. (2011). PLS-SEM: Indeed a Silver Bullet, Journal of Marketing Theory and Practice 19(2): 139-152.

Henseler, J., Ringle, C.M. and Sarstedt, M. (2015). A New Criterion for Assessing Discriminant Validity in Variance-Based Structural Equation Modeling, Journal of the Academy of Marketing Science 43(1): 115-135.

Howells, J. (2006). Intermediation and the Role of Intermediaries in Innovation, Research Policy 35: 715-728.

Huckman, R., Staats, B. and Upton, D. (2009). Team Familiarity, Role Experience, and Performance: Evidence from Indian Software Services, Management Science 55(1): 85-100.

Kern, T., Willcocks, L.P. and van Heck, E. (2002). The Winner's Curse in IT Outsourcing: Strategies for Avoiding Relational Trauma, California Management Review 44(2): 47-69.

Kotlarsky, J., Scarbrough, H. and Oshri, I. (2014). Coordinating Expertise Across Knowledge Boundaries in Offshore-Outsourcing Projects: The Role of Codification, MIS Quarterly 38(2): 607-627.

Lacity, M.C., Khan, S., Yan, A. and Willcocks, L.P. (2010). A Review of the IT Outsourcing Empirical Literature and Future Research Directions, Journal of Information Technology 25(4): 395-433.

Lacity, M.C. and Willcocks, L.P. (2013). Beyond Cost Savings: Outsourcing Business Processes for Innovation, Sloan Management Review 54(3): 63-69.

Lacity, M.C. and Willcocks, L.P. (2014). Business Process Outsourcing and Dynamic Innovation, Strategic Outsourcing: An International Journal 7(1): 66-92.

Lacity, M.C., Khan, S. and Yan, A. (2016). Review of the Empirical Business Services Sourcing Literature: An Update and Future Directions, Journal of Information Technology 31(3): 269-328.

Lawson, B., Tyler, B.B. and Cousins, P.D. (2008). Antecedents and Consequences of Social Capital on Buyer Performance Improvement, Journal of Operations Management 26, 446-460.

Lee, K.C. and Chung, N. (2009). Understanding factors affecting trust in and satisfaction with mobile banking in Korea: A modified DeLone and McLean's model perspective, Interacting with computers 21(5-6): 385-392.

MacKenzie, S.B., Podsakoff, P.M. and Podsakoff, N.P. (2011). Construct Measurement and Validation Procedures in MIS and Behavioral Research: Integrating New and Existing Techniques, MIS Quarterly 35(2): 293-334.

Mahnke, V., Wareham, J. and Bjorn-Andersen, N. (2008). Offshore Middlemen: Transnational Intermediation in Technology Sourcing, Journal of Information Technology 23(1): 18-30.

Morgan, T. (2003). Collaborative Innovation: How Clients and Service Providers Can Work by Design to Achieve It, London: Business Express Press.

Oshri, I., Kotlarsky, J. and Gerbasi, A. (2015). Strategic Innovation Through Outsourcing: The Role of Relational and Contractual Governance, Journal of Strategic Information Systems 24(3): 203-216.

Rottman, J. and Lacity, M. (2006). Proven practices for effectively offshoring IT work, Sloan Management Review 47(3): 56-63.

Soderlund, M. (2002). Customer Familiarity and Its Effects on Satisfaction and Behavioral Intentions, Psychology \& Marketing 19(10): 861-879.

Stewart, J.K. and Hyysalo, S. (2008). Intermediaries, Users and Social Learning in Technological Innovation, International Journal of Innovation Management 12(3): 295-325.
Su, N., Levina, N. and Ross, J. (2016). The Long-Tail Strategy of IT Outsourcing, Sloan Management Review, Winter 57(2): 81-89.

Tadelis, S. (2007). The Innovative Organization: Creating Value Through Outsourcing, California Management Review 50(1): 261-277.

Tran, Y., Hsuan, J. and Mahnke, V. (2011). How Do Innovation Intermediaries Add Value? Insight from New Product Development in Fashion Markets, R\&D Management 41(1): 80-91.

Weeks, M.R. and Feeny, D. (2008). Outsourcing: From Cost Management to Innovation and Business Value, California Management Review 50(4): 127-146. Whitley, E.A. and Willcocks, L.P. (2011). Achieving Step-Change in Outsourcing Maturity: Toward Collaborative Innovation, MIS Quarterly Executive 10(3): 95-107.

Whitten, D. and Leidner, D. (2006). Bringing IT back: An analysis of the decision to backsource or switch vendors, Decision Sciences 37(4): 605-621.

\section{About the Authors}

Ilan Oshri is a Professor of Technology and Globalisation at Loughborough School of Business, UK. His research interests revolve around outsourcing and offshoring of knowledgeintensive business processes and services, knowledge and expertise coordination in complex organizational settings. He has published his work in numerous journals including MIS Quarterly, Long Range Planning, European Journal of Information Systems and Journal of Strategic Information Systems. Ilan has co-authored or co-edited 14 books, among them The Handbook of Global Outsourcing and Offshoring (Palgrave Macmillan, 2015, with J. Kotlarsky and L. P. Willcocks). Ilan serves as Senior Editor for Journal of Information Technology and is the co-founder of the annual Global Sourcing Workshop and the Asia-Pacific Global Sourcing Conference.

Daria Arkhipova is a postdoctoral research fellow at the Department of Management at Ca' Foscari University of Venice. Daria's current research interests include informational technology, strategy, competitive interaction and managerial decision-making. She has been an active collaborator of the Digital Enterprise Lab (DEL) and Center of Experimental Research in Management and Economics (CERME).

Giovanni Vaia is a assistant professor with tenure at Ca' Foscari University Venice at the Department of Management where he teaches Global Sourcing and Digital Management. Giovanni Vaia's interests include organization design and general management with a specific focus on digital transformation, information systems, network governance and outsourcing, performance management. He is the founder and the Scientific Director of the Digital Enterprise Lab (DEL) at Ca' Foscari. 